\title{
Metal Organic Frameworks Loaded Polymeric Membranes in Pervaporative Desalination Applications: A Mini Review
}

\author{
Derya Unlu ${ }^{*}$ \\ 1* Department of Chemical Engineering, Bursa TechnicalUniversity, 16310 Bursa, Turkey
}

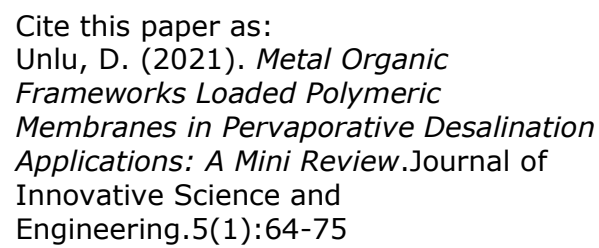

*Corresponding author: Derya Unlu E-mail:derya.unlu@btu.edu.tr

Received Date:25/08/2020

Accepted Date:17/01/2021

(C) Copyright 2021 by

Bursa Technical University. Available online at http://jise.btu.edu.tr/

\section{cc) (7) (8)}

The works published in Journal of Innovative Science and Engineering (JISE) are licensed under a Creative Commons Attribution-NonCommercial 4.0 International License.

\section{Abstract}

Pervaporative desalination is an efficacious method to obtain fresh water from saline water sources. High salt rejection and capacity to cope with high-salt concentration water solutions are important advantages of pervaporation process. To improve pervaporative desalination performance, researches concentrate on novel membrane types. Water stable metal organic frameworks loaded membranes attract substantial attention among novelty membrane applications. This study focuses on pervaporative desalination with MOF loaded polymeric membrane. First of all, the features of MOFs, synthesis methods, usage areas are explained. Then, MOFs loaded mixed matrix membranes, production methods, used MOF types in membranes and applications in pervaporative desalination are examined. At the end of the study, future expectation on the desalination applications of MOF loaded membranes are presented as concluding remarks. Metal organic framework loaded polymeric membranes are seen as promising candidates to obtain drinking water with high separation yield in pervaporative desalination process.

Keywords: Desalination, membrane, metal organic framework, pervaporation 


\section{Introduction}

The overconsumption of available water reserves and making the available resources unusable day by day have made the search for clean water even more important in recent years. With the increment of the world population and the development of the industry, water consumption is constantly increasing. Clean water is insufficient. Therefore, major problems arise in terms of industrial and economic development. To overcome the water scarcity is possible with water resources management and cleaning the existential water resources. There are a great number of countries with a coastline. The high level of salt in the seawater prevents them from using the seawater as direct drinking water and using this resource for agricultural purposes [1]. The remove of the salt from the saline water is called desalination.

Nowadays, desalination studies are usually carried out through heat treatments such as multi-stage sudden distillation (MSF) and multi-process distillation (MED) and membrane processes such as reverse membrane osmosis (RO) and pervaporation [2]. In desalination applications, membrane processes have superiority thanks to its high separation performance, energy saving, easy integration to the industrial systems. Among these membrane processes, pervaporation has an important position [3]. Pervaporation (PV) is a membrane process that uses dense membrane, and separation is carried out by permeation and evaporation steps. Pervaporation is an important alternative in desalination applications with its energy saving, resistance to pollution, high separation performance considering flux and salt retention rates [4].

The driving force for the perform separation in pervaporation is the difference between partial pressures of the components. This driving force is created by using a vacuum [5]. The solution-diffusion model is the separation mechanism of the pervaporation process. According to this mechanism, sorption, diffusion and desorption steps occur [6]. Membrane allows the freshwater from the membrane and retains the salt. The choice of the membrane is rather important for the pervaporation process.

Metal organic frameworks loaded mixed matrix membranes are a significant alternative for pervaporation process. Metal organic frameworks are seen as developing materials due to their features such as large surface area, changeable porosity, high adsorption ability and compatibility with polymer chains for mixed matrix membranes [7].

In this research, the application of metal organic frameworks loaded membranes in pervaporative desalination has been investigated. The properties of MOF, production methods, MOF types has been reviewed. The applications of pervaporative desalination have been undertaken in recent years and the future of the application has been summarized.

\section{Metal Organic Frameworks (MOF)}

Scientific studies have intensified on the nanoparticles in recent years. Particularly, the researches in the last 10 years have shown the interesting features and superior molecular structures of metal organic frameworks. In addition to these advantages of MOFs, nanoparticles have exhibited remarkable features in promising areas. The storage and separation 
of gases and the catalyst or sensor applications can be given as an example for these remarkable applications. Metal organic frameworks (MOF) are one of the members of the "organic-inorganic hybrid molecules" nanomaterial class and consist of an organic binder and metal ion. The most important feature of MOFs is that they can be prepared in desired pore sizes and surface areas [8]. The general structure of MOF is shown in Figure 1. Metal ions are connected by the organic ligand and form the framework with the large void volume.

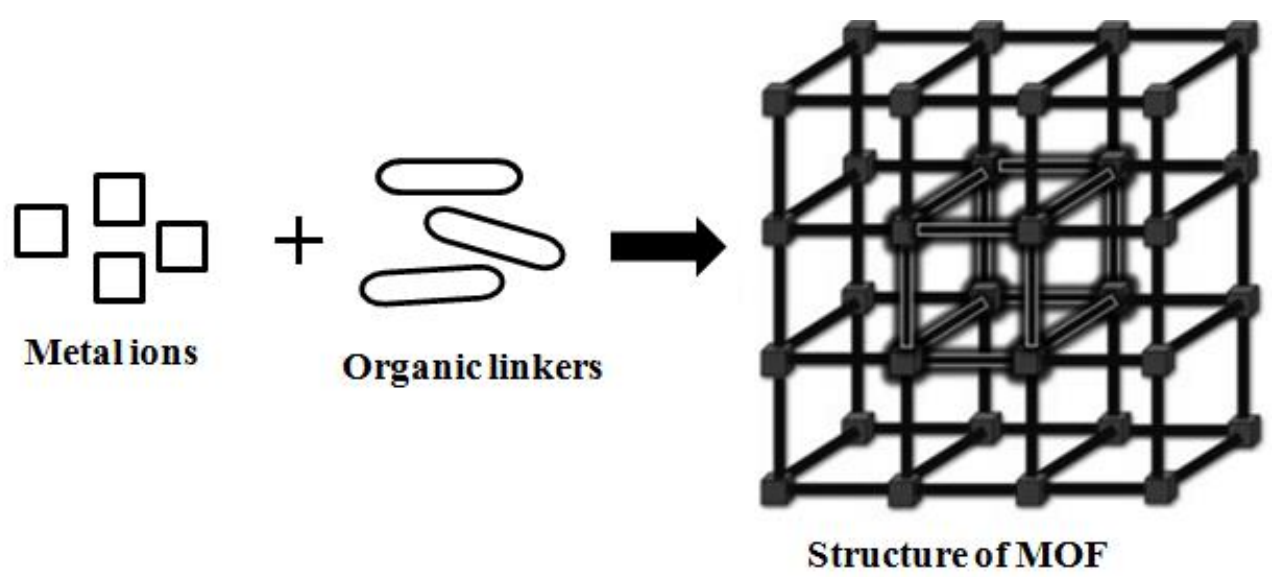

Figure 1: Structure of MOF [11]

The reasons of why the metal organic frameworks have been used as important research subject in recent years;

- wide surface areas,

- high pore volume,

- flexible frameworks,

- $\quad$ high gas adsorption capacity [9].

Pore size is an important feature of MOFs. This feature is related to the organic ligand in the structure of MOF. The high pore size of MOF is provided with the choice of appropriate carboxylate binder. The MOF becomes a small porous nanomaterial with the usage of long binders. The porosity can be adjusted during synthesis. To obtain MOF by the desired property, the appropriate materials according to the properties should be chosen and used in the synthesis process. Molecular size and gaps can be associated with the length and functionality of the used organic structures [10].

Examples of the most suitable organic ligands which bond the metal ions in the MOF structure are imidazoles, carboxylates, phosphonates, sulfonates and pyridines. By connecting the organic ligand with a metal ion, a metal-oxygen interaction and the polyhedron structure occur.

MOFs are used in various industrial applications. According to changes in pore size, MOFs can be used in separation, purification, and catalysis processes. MOFs can be classified according to pore size. The first one of them is microporous structures and the pore diameter is less than $2 \mathrm{~nm}$. While the pore diameter of the mesoporous structures varies between 2 and $50 \mathrm{~nm}$, the diameter of the macroporous structures is greater than $50 \mathrm{~nm}$ [11]. 


\subsection{Synthesis of Metal-Organic Frameworks}

Metal-organic frameworks can be fabricated by heating, sound waves, microwave method, electrochemical methods or mechanically. Besides, solvothermal and hydrothermal synthesis methods are frequently applied. The water above the normal boiling point and pressure is used to accelerate the reaction between the solids. If a solvent other than water is used, this method is defined as the solvothermal method. The sizes and surface shapes of metal-organic frameworks can be changed with the conditions of the synthesis. Thin film, membrane or various composites can be prepared. To achieve a high quality single crystal for structural analysis, the synthesis reaction should proceed slowly.

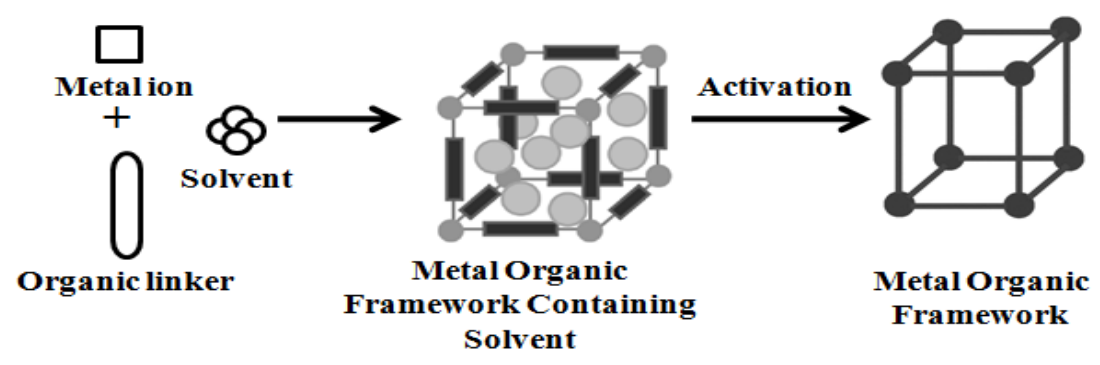

Figure 2: The synthesis steps of metal-organic frameworks [12]

The preparation steps of metal-organic frameworks are shown schematically in Figure 2. The components are reacted under suitable conditions, and metal-organic frameworks containing solvent are prepared and the pores of frameworks are emptied by the activation process for use in different applications [12].

\subsection{Usage Areas of Metal-Organic Frameworks}

Metal-organic frameworks can be utilized in the following areas:

- the storage of carbon dioxide, hydrogen and other gases

- in purification processes

- separation of gases and liquids from each other

- shape and size selective catalysis

- drug storage and delivery

- $\mathrm{CO}_{2}$ reduction and various organic conversion processes

- luminescence and magnetic sensor [12].

\section{Metal Organic Frameworks Loaded Mixed Matrix Membranes}

Polymeric membranes that have low production cost and high mechanical resistance remain in the background compared to inorganic membranes which have high permeability and selectivity. Inorganic membranes have disadvantages such as complex synthesis methods, low repeatability, high cost and low mechanical stability. Considering these circumstances, researchers concentrate on the development of mixed matrix membranes (MMM) for the improvement 
of permeability and selectivity of the polymeric membranes. The general purpose of these studies is to combine the permeability and selectivity properties of inorganic membranes with the mechanical, thermal and barrier properties of polymer membranes [13-15].

The usage of nanomaterials in mixed matrix membranes has gained importance in recent years. The fumed silica, siliconcontaining particles, carbon molecular sieves or carbon nanotubes, inorganic oxides, titanium dioxide, magnesium oxide, zeolites, phthalocyanines, fullerene and metal organic frameworks (MOFs) can be given as examples for nanomaterials [16-17]. However, there are ongoing problems due to incompatibility between polymer and nanomaterials such as the low separation performances and large-scale industrial reproducibility of mixed matrix membranes. The bad interaction between the nanomaterials and the polymer, the sedimentation and aggregation of the nanomaterials can be given as an example for these problems. For example, incompatibility between polymer - inorganic additive can lead to the generation of non-selective gaps in the polymer - additive interface [14, 16, 18].

\subsection{Metal Organic Frameworks Species for Mixed Matrix Membranes in Desalination}

Mixed matrix membranes are rather popular in membrane science. Metal organic frameworks are important materials for the production of mixed matrix membranes. Mixed matrix membranes are synthesized by comprising metal organic frameworks into the polymer matrix. UiO-66 is one of the MOF which has used frequently in pervaporation and reverse osmosis application for desalination due to the high chemical and thermal stability. When compared with the pristine polymeric pervaporation membranes, MOF loaded polymeric membranes have high water flux and ion rejection [19].

UiO-66 can be modified by binding the functional groups such as $-\mathrm{NH}_{2},-\mathrm{OH},-\mathrm{COOH},-\mathrm{CH}_{3},-\mathrm{Br},-\mathrm{F}$. Among these, UiO-66- $\mathrm{NH}_{2}$ is more preferred for separation applications. UiO-66- $\mathrm{NH}_{2}$ has pore size (approximately $\sim 0.52$ ) between the size of water molecules $(0.26 \mathrm{~nm})$ and hydrated ions. The other ions like $\mathrm{Na}, \mathrm{Mg}, \mathrm{Cl}$ has higher molecular size than UiO-66- $\mathrm{NH}_{2}\left(\mathrm{Na}^{+} 0.72 \mathrm{~nm}, \mathrm{Ca}^{2+} 0.82 \mathrm{~nm}, \mathrm{Mg}^{2+} 0.86 \mathrm{~nm}, \mathrm{~K}^{+} 0.66 \mathrm{~nm}, \mathrm{Cl}^{-} 0.66 \mathrm{~nm}\right)$. Therefore, the UiO-66-NH membranes display high ion rejections in desalination [20]. The frameworks of UiO-66 and UiO-66- $\mathrm{NH}_{2}$ are demonstrated in Figure 3.

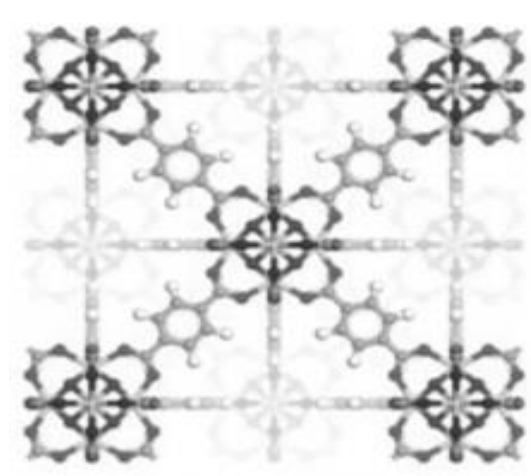

(a)

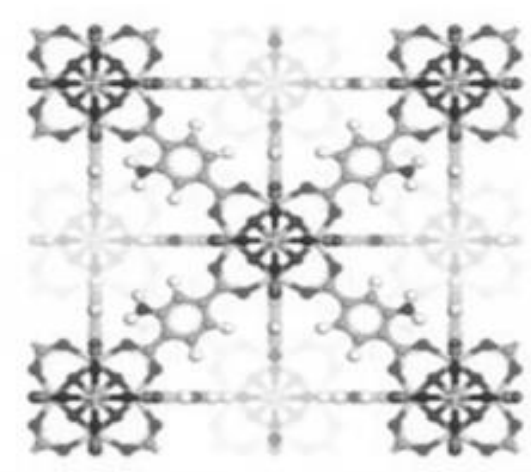

(b)

Figure 3: The structures of UiO-66 (a) and UiO-66- $\mathrm{NH}_{2}$ (b) [21] 
HKUST-1 is another MOF type. Its structure can be seen in Figure 4. It is generally used in gas separation applications. Despite easy fabrication and high permeability, some features of HKUST-1 restrict the usage of it in water treatment applications. The interaction between $\mathrm{Cu}$ ions in HKUST-1 and oxygen in the water results in the decomposition of the MOF structure. On the other hand, HKUST-1 exhibits stable behavior for months in aqueous solvent mixtures. Therefore, the studies have been conducted for the improvement of durability of HKUST-1 in aqueous solution. In this way, HKUST-1 has been embedded in the polymeric matrix. Therefore, HKUST-1 will be used for water purification applications. Under these conditions, the $\mathrm{Cu}$ atoms in framework interact with the $\mathrm{O}$ atoms in the polymers, thus the interaction between the water molecules with the $\mathrm{Cu}$ atoms is prevented. The durability of HKUST-1 in water increases in this situation [19].

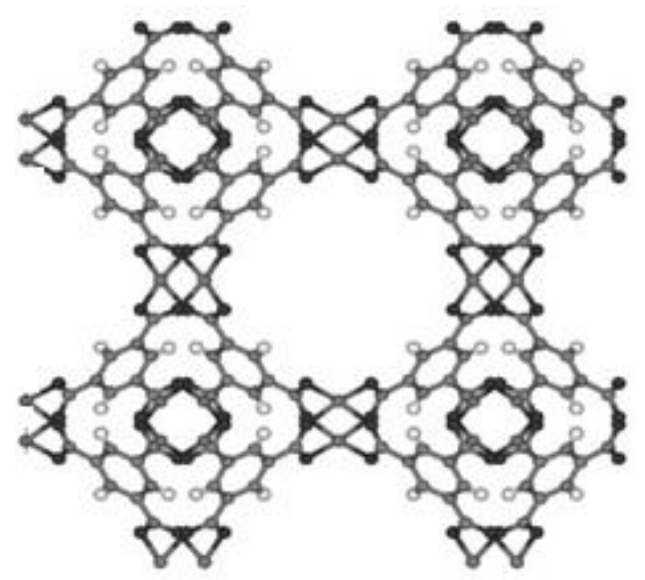

Figure 4: The structure of HKUST-1 [22]

\subsection{Synthesis of Metal Organic Framework Loaded Membranes}

MMMs are synthesized by embedding the particles in a polymeric matrix. These materials combine the features of polymer and additive such as the mechanical stability of polymer and porosity of MOF. In a synthesis of MMM, the MOF is distributed in a polymer solution. This solution is cast on a plate and released to drying. These MOF membranes do not require the supporting layer. MMMs have high functionality compared with substrate-supported membranes. MMMs utilize the synthesized MOF particles. Therefore, a broad range of MOFs and mixtures of MOFs can be used in MMMs. While some of the MOFs can form the polycrystalline films, many other significant MOFs cannot form the continuous MOF films. RMOF-1, HKUST-1, UiO-66 and ZIFs can be produced as a pristine membrane. However, the production of the pristine membrane is impossible with MOFs like MIL-101, UiO-67 and NU-1000. Therefore, these MOFs can be used easily in MMM. Metal organic framework loaded polymeric membranes can be seen in Figure 5. 


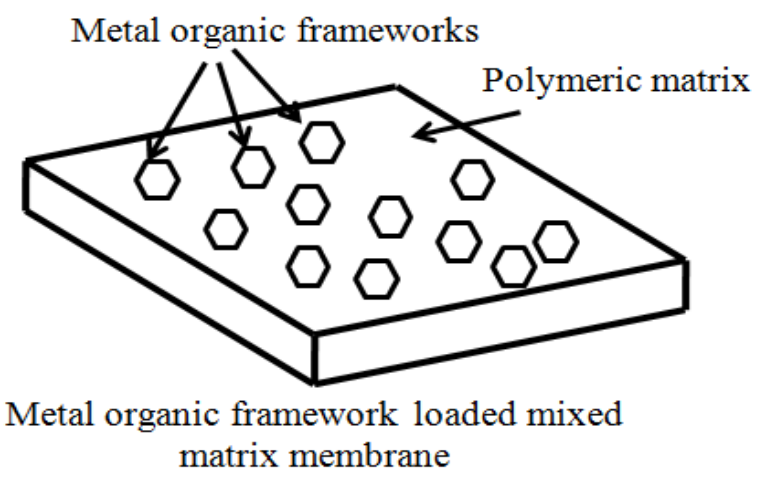

Figure 5: Metal organic framework loaded mixed membranes [23]

The aim of adding the MOFs into the polymeric membrane is to improve the features of pristine polymeric membranes. MOFs improve the separation capacity of the membranes, increases the rigidness and decrease the swelling degree of the membrane. For instance, in a study, MOF loaded membrane increases the flux value $162 \%$ compared with a pristine polymeric membrane. This result is related to the presence of MOF in the polymeric membrane. MOF increases the flux value, and selectivity value is conducted by the polymer. MMMs display high permeability as compared to the pristine polymer membranes.

The aggregation and poor dispersion of the MOFs in MMM is important to challenge. Under these conditions, the void defects form in the membrane. These voids provide wide diffusion channels along the membrane, and the separation efficiency and performance reduce. To overcome these problems, several techniques such as spray self-assembly, sonication and interfacial diffusion have been used in the synthesis of MMM. Besides, the change of MOF surface chemistry decreases the aggregation and macrovoid formation [23].

\section{Pervaporation}

Pervaporation is membrane-based separation process, which is used for separation of binary or multicomponent mixtures of various organic liquids. In other words, pervaporation is a membrane process, which is used for separation of liquidliquid mixtures. It has a potential to substitute the conventional separation process, "distillation", because distillation remains incapable for heat sensitive and azeotropic mixtures. Different separation techniques such as adsorption, azeotropic distillation, and liquid-liquid extraction are used to overcome the limitations of conventional distillation. However, these separation methods are energy-intensive processes and cause environmental pollution by producing waste. Pervaporation process displays advantages on the separation of liquid mixtures due to its mild working conditions, energy saving, easy usage and its eco-friendly credentials [24-25].

The separation of liquid-liquid mixtures by pervaporation is based on the partial evaporation from a dense membrane. One of the component from the liquid mixture passes selectively through the dense membrane in pervaporation. The liquid component leaves the membrane as vapor phase, and the vapor stream is condensed in the cold traps to change the phase as liquid again [24-25]. 


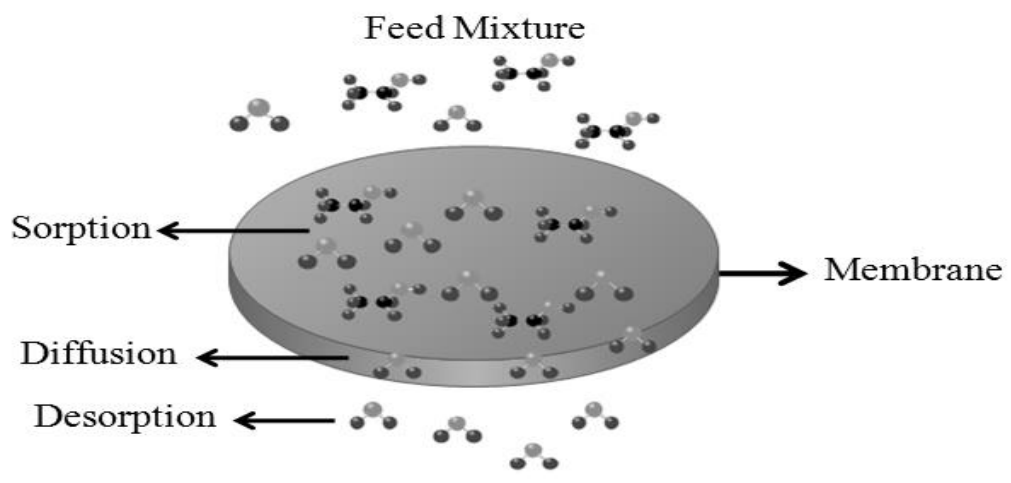

Figure 6: The solution-diffusion model

The solution-diffusion model is the mass transport mechanism for pervaporation processes (Figure 6). According to this model, the transport of the selective component along the membrane comprises three steps:

I. sorption of the component penetrating the membrane from the feed side,

II. diffusion of the selective component along the membrane,

III. evaporation of the permeate stream in the downside of the membrane [26].

The driving force in the pervaporation process is the chemical potential gradient. It is created by the partial vapor pressure gradient between the liquid feed and the permeate stream. The gradient is achieved by applying low pressure from the downstream of the membrane. This low pressure creates low activity on the downstream of the membrane compared to the high activity on the feed side. The differences of activities are resulted in driving force [27].

The performance of the pervaporation process depends on the properties of the membrane. To obtain a good pervaporation performance, it is very important to prepare the desired membranes [28]. Some features should be considered in the selection of polymeric material for separation. These are high chemical resistance, good sorption and diffusion capacity and mechanical and thermal strength of the polymer film. Membrane should be able to interact with one of the components in the feed mixture. Solubility parameter and polarity are important parameters in the interaction of membrane materials with the feed mixture and separation success [29]. Therefore, the choice of appropriate polymer and additive material has critical importance to obtain a good separation.

\section{Literature Researches}

The use of metal organic frameworks loaded polymeric membranes in pervaporative desalination process is a rather novelty application. In the literature, a limited number of pervaporative desalination studies were carried out by using MOF loaded polymeric membrane. 
Jee et al. prepared the hydrophilic metal-organic framework $\mathrm{Cu}_{3}(\mathrm{BTC})_{2}$ additives loaded PVDF membranes. In addition to $\mathrm{Cu}_{3}(\mathrm{BTC})_{2}$, acid-containing $\mathrm{Cu}_{3}(\mathrm{BTC})_{2}$ was produced and added to the PVDF membrane. The influences of the $\mathrm{Cu}_{3}(\mathrm{BTC})_{2}$ and acid-containing $\mathrm{Cu}_{3}(\mathrm{BTC})_{2}$ on the pristine PVDF membranes were examined in flux and rejection values. MOFs were characterized by XRD and XPS. MOF loaded polymeric membranes were analyzed by FE-SEM and contact angle analysis. The obtained water fluxes of MOF loaded PVDF and acid-MOF loaded PVDF membranes were approximately 2 and 4 times greater than those of the pristine PVDF membrane. The acid-containing $\mathrm{Cu}_{3}(\mathrm{BTC})_{2}$ displayed a more durable structure according to $\mathrm{Cu}_{3}(\mathrm{BTC})_{2}$ and acid-containing $\mathrm{Cu}_{3}(\mathrm{BTC})_{2}$ was immobilized properly in the PVDF membrane. Therefore, the leaching of metals to the solution was prevented. As a result, MOF loaded polymeric membranes can be used as a significant alternative in water treatment [30].

Liang et al. synthesized MIL-53(Al) loaded PVA composite membrane. After the addition of MIL-53(Al) to membrane, composite MOF loaded membrane was prepared by dip-coating on PVDF hollow fiber membrane. Separation performance was enhanced with the addition of UiO-66. UiO-66 has a super hydrophilic nature. MIL-53(Al) was added to the PVA solution before the dip coating. The characterization of MIL-53(Al) was carried out by using FTIR, TGA and SEM. The membrane was characterized by FIB-SEM. Desalination tests were performed in $100 \mathrm{~g} / \mathrm{L} \mathrm{NaCl}$ solution. The permeate analysis was carried out by conductivity and inductively coupled plasma mass spectrometry (ICP-MS). MOF loaded membrane displayed superior separation performance with the salt rejection of $>99.999 \%$ [31].

According to the author's research, there are only two studies about the pervaporative desalination with MOF loaded polymeric membrane in the relevant literature. In the other studies, directly pristine MOF membrane without polymer are used. However, these studies are also limited.

Liu et al. used highly water stable UiO-66 membranes for desalination. Zirconium(IV) based metal-organic framework (Zr-MOF) membrane was produced on alumina support by utilizing in-situ solvothermal production technique. The synthesized membrane exhibited excellent multivalent ion rejection and chemical and mechanical stability. The membrane was used up to 170 hours in the desalination process [32].

Wan et al. fabricated UiO-66- $\mathrm{NH}_{2}$ membranes for desalination of seawater. Membranes were fabricated on the 3aminopropyl-triethoxysilane (APTES) modified $\mathrm{Al}_{2} \mathrm{O}_{3}$ support. APTES was used to immobilize the metal ions onto the support layer. Membranes were characterized by SEM and XRD. The middle pore magnitude and the hydrophilic regions in the UiO-66- $\mathrm{NH}_{2}$ were responsible for the high separation performances. At the end of the study, the water flux and ion rejections were acquired as $7.5 \mathrm{k} / \mathrm{m}^{2}$ hand $99.7 \%$, respectively. Moreover, the UiO-66- $\mathrm{NH}_{2}$ membranes can be used for $120 \mathrm{~h}$ at $348 \mathrm{~K}$ without degradation in desalination [20].

\section{Conclusion}

Pervaporation is a favorable technique for desalination. Polymeric, inorganic, blend, hybrid, mixed matrix and composite membranes which are used in pervaporative desalination, show excellent separation performance with high fluxes and 
salt rejection. MOFs are new approaches to the membrane technologies. MOFs are suitable materials due to changeable features of them such as surface area, chemical, and structural for the membrane applications.

The improvements in pervaporation regarding to permeability, selectivity and durability will enhance the competition capacity of the process. Innovative membrane materials and production methods are rather important for this aspect. Metal organic framework loaded polymeric membranes are significant alternatives. The studies showed that metal organic frameworks have high flux and rejection values. However, there are a limited number of studies about pervaporative desalination in the related literature. More efforts should be made to produce metal organic framework loaded polymeric membranes and to use them in pervaporative desalination because desalination is an important solution to obtain drinking water. Herein, it gains great importance to produce a membrane with high separation yield. Metal organic framework loaded polymeric membranes are promising candidates for this purpose.

\section{References}

[1] Yiğit, A. and Atmaca, İ. (2010). Güneş Enerjisi, Alfa-AktüelYayınları, Bursa, Turkey, 1st Edition, 216 p. ISBN: 9789752531673.

[2] Humplik, T., Lee, J., O’Hern, S.C., Fellman, B.A., Baig, M.A., Hassan, S.F., Atieh, M.A., Rahman, F., Laoui, T., Karnik, R. and Wang, E.N. (2011). Nanostructured materials for water desalination. Nanotechnology,22:292001.

[3] Drioli, E., Stankiewicz, A.I. andMacedonio, F. (2011). Membrane engineering in process intensification an overview. Journal of Membrane Science, 380:1-8.

[4] Wang, Q., Li. N., Bolto, B., Hoang, M. andXie, Z. (2016). Desalination by Pervaporation A review. Desalination, 387:46-60.

[5] Huang, R.Y.M. (1991). Pervaporation Membrane Separation Process, Elsevier, Amsterdam, The Netherlands, 1st Edition, 549 p. ISBN:9780444882271.

[6] Noble, R.D. and Stern, S.A. (1995). Membrane Separations Technology, Principles and Applications, Elsevier, Amsterdam, The Netherlands, 1st Edition, 738 p. ISBN:9780444816337.

[7] Xu, Y.M. and Chung, T.S. (2017). High-performance UiO-66/polyimide mixed matrix membranes for ethanol, isopropanol and n-butanol dehydration via pervaporation. Journal of Membrane Science, 531:16-26.

[8] Furukawa, H., Cordova, K.E., O'Keeffe, M. andYaghi, O.M. (2013). The chemistry and applications of metalorganic frameworks. Science, 342:1230444.

[9] Kurhall, K.S. (2013). An alternative solution for the global warming and the climate change: metal organic frameworks (MOF); synthesis and $\mathrm{CO}_{2}$ capture, MScThesis. University of Marmara, İstanbul, Turkey. 76 p.

[10] Rowsell, J.L.C. andYaghi, O.M. (2004). Metal-organic frameworks: a new class of porous materials. Microporous and Mesoporous Materials, 73:3-14.

[11] Hekimoglu, G.P. (2016). Preperation of metal organic frameworks (MOFs) and polymeric nanocomposite membranes and evaluation of their gas permeability properties, MSc Thesis.University of Y1ldiz Technical, İstanbul, Turkey. $84 \mathrm{p}$. 
[12] Usta, S. (2016). Synthesis, characterization and catalytic application of some new metal-organic frameworks. MScThesis.University of RecepTayyipErdoğan, Rize, Turkey. 81 p.

[13] Cejka, J., Bekkum, H., Corma, A. andSchüth, F. (2007). Zeolite membranes - synthesis, characterization and application, Introduction to Zeolite Science and Practice, Edited by Julbe A. Elsevier, Amsterdam, Netherlands. pp. 181-219. ISBN:9780080534794.

[14] Perez, E.V. (2009). Mixed-Matrix Membranes Containing Metal-Organic Frameworks for Gas Separations, PhD Thesis. University of Texas. Dallas, Richardson, TX, USA.

[15] Saracco, G., Neomagus, H.W.J.P., Versteeg, G.F. andSwaaij, W.P.M. (1999). High-temperature membrane reactors: potential and problems. Chemical Engineering Science, 54: 1997-2017.

[16] Basu, S., Cano-Odena, A. andVankelecom, I.F.J. (2010). Asymmetric Matrimid $® /[C u 3(B T C) 2]$ mixed-matrix membranes for gas separations. Journal of Membrane Science, 362: 478-487.

[17] Bushell, A.F., Attfield, M.P., Mason, C.R., et al., (2013). Gas permeation parameters of mixed matrix membranes based on the polymer of intrinsic microporosity PIM-1 and the zeoliticimidazolate framework ZIF8. Journal of Membrane Science, 427: 48-62.

[18] Cacho-Bailo, F., Seoane, B., Téllez, C. and Coronas, J. (2014). ZIF-8 Continuous Membrane on Porous Polysulfone for Hydrogen Separation. Journal of Membrane Science, 464: 119-126.

[19] Dahanayaka, M., Babicheva, R., Chen, Z., Law, A.W.K, Wu, M.S. and Zhou, K. (2020). Atomistic simulation study of GO/HKUST-1 MOF membranes for seawater desalination via pervaporation. Applied Surface Science,503: 144198.

[20] Wan, L., Zhou, C., Xu, K., Feng, B. and Huang, A. (2017). Synthesis of highly stable UiO-66-NH2 membranes with high ions rejection for seawater desalination. Microporous and Mesoporous Materials, 252: 207-213.

[21] Gong, J., Katz, M.J., Kerton, F. M. (2018). Catalytic conversion of glucose to 5-hydroxymethylfurfural using zirconium-containing metal-organic frameworks using microwave heating. RSC Advances, 8(55):3161831627.

[22] O'Neill, L.D., Zhang, H., Bradshaw, D. (2010). Macro-/microporous MOF composite beads. Journal of Materials Chemistry, 20(27):5720-5726.

[23] Jr, M.S.D., Moreton, J.C., Benz, L. and Cohen, S.M. (2016). Metal-organic frameworks for membrane-based separations. Nature Reviews Materials, 1: 16078.

[24] Kujawski, W. (2000). Application of Pervaporation and Vapor Permeation in Environmental Protection. Polish Journal of Environmental Studies, 9:13-26.

[25] Baker R. W. (2000). Membrane separation, Encyclopedia of Separation Science, Edited by Wilson I. D., Adlard E. D., Cooke M., Poole C. F., Academic Press, Germany, pp. 205-209. 2000. ISBN:978-0-12-2267703.

[26] Ong, Y.K., Shi, G.M., Le, N.L., Tang, Y.P., Zuo, J., Nunes, S.P. and Chung T.S. (2016). Recent membrane development for pervaporation processes. Progress in Polymer Science, 57:1-31.

[27] Gugliuzza A., Basile A. (2014). Membranes for Clean and Renewable Power Applications, Woodhead Publishing, UK, 1st Edition, 438 p. ISBN:9780857095459.

[28] Smitha, B., Suhanya, D., Sridhar, S., Ramakrishna, M. (2004). Separation of organic-organic mixtures by pervaporation a review. Journal of Membrane Science, 241:1-21. 
[29] Das, S., Banthia, A. K., Adhikari, B. (2007). Improved conversion to ethyl acetate through removal of water of esterification by membrane pervaporation. Indian Journal of Chemical Technology, 14: 552-559.

[30] Jee, K.Y., Kim, J.S., Kim, J. and Lee, Y.T. (2015). Effect of hydrophilic $\mathrm{Cu}_{3}(\mathrm{BTC})_{2}$ additives on the performance of PVDF membranes for water flux improvement. Desalination and Water Treatment, 57:1-9.

[31] Liang, W., Li, L., Hou, J., Shepherd, N.D., Bennett, T.D., D’Alessandro, D.M. and Chen, V. (2018). Linking defects, hierarchical porosity generation and desalination performance in metal-organic frameworks. Chemical Science, 9:3508-3516.

[32] Liu, X., Demir, N.K., Wu, Z., Li, K. (2015). Highly Water-Stable Zirconium Metal-Organic Framework UiO66 Membranes Supported on Alumina Hollow Fibers for Desalination. Journal of the American Chemical Society, 137: 6999-7002. 